Institute of $\mathbf{F}_{\text {ood and }} \mathbf{A g r i c u l t u r a l}_{\text {ciences }}$

\title{
Enviroshopping: Buy Smarter ${ }^{1}$
}

Marie Hammer and Joan Papadi ${ }^{2}$

Each week, a ritual called "taking out the garbage" is repeated in nearly every household. In neatly tied-up trash bags are the unwanted fragments of our daily lives. Once deposited at curbside or in a dumpster, the garbage (technically called solid waste) is picked up, hauled to a landfill for disposal and forgotten by those who generated it.

Floridians throw away about 8 pounds of garbage per person each day, double the national average. The Florida rate is increased somewhat by the trash from our visitors (35 million a year) and an active construction industry which generates a large amount of debris.

All this garbage is "Here Today...Here Tomorrow." We must be responsible not only for what we consume, but also for what we dispose. What we dispose of wastes energy and materials and can release pollutants into the environment.

The environmental impact of trash begins long before it becomes trash. It starts with the mining or extraction of raw materials, and continues when the raw materials are transported to the factory. When the products are manufactured, stored, and transported to the retail store, pollution can occur. Each incident of pollution may be small, but added together they contribute to the pollution problems that are of so much concern today. By reducing the amount of waste you produce, you save energy and reduce pollution.

\section{Packing with a Purpose}

There are a number of ways to tackle the problem of garbage. One way starts with you and the products you buy. You can shop with the environment in mind. Try to buy products that:

- make the best use of energy resources;

- don't pollute our air and water;

- are reusable or recyclable;

- are made from plentiful resources or from recycled material;

- use a minimum of materials in design and packaging.

1. This document is FCS 3158, one of a series of the Department of Family, Youth and Community Sciences, Florida Cooperative Extension Service, Institute of Food and Agricultural Sciences, University of Florida. Publication date: July 2002. First published: June 1991. Revised: July 2002 Please visit the EDIS Web site at http://edis.ifas.ufl.edu

2. Written by Marie Hammer, former Professor, Housing/Home Environment, Department of Family, Youth and Community Sciences and Joan Papadi, former Family and Consumer Sciences Extension Agent, Cooperative Extension Service, Institute of Food and Agricultural Sciences, University of Florida, Gainesville, 32611 and reviewed by Nayda I. Torres, Professor, Family and Consumer Economics, Department of Family, Youth and Community Sciences, Cooperative Extension Service, Institute of Food and Agricultural Sciences, University of Florida and Dale Dorman, Extension Housing and Environment Specialist - Emeritus, Cooperative Extension Service, University of Georgia.

The Institute of Food and Agricultural Sciences is an equal opportunity/affirmative action employer authorized to provide research, educational information and other services only to individuals and institutions that function without regard to race, color, sex, age, handicap, or national origin. For information on obtaining other extension publications, contact your county Cooperative Extension Service office. Florida Cooperative Extension Service / Institute of Food and Agricultural Sciences / University of Florida / Christine Taylor Waddill, Dean 
When you shop for products like these, you are "Enviroshopping."

\section{Packaging: Convenience in Plastic and Paper}

Thirty percent of our household waste is packaging. Most of what we buy was wrapped in a package at some time on its way from producer to consumer. Much of it is in several layers of packaging. Is all of that really necessary?

Packaging is an essential part of our marketing and distribution systems. It performs several functions:

- Protects food from light, heat, oxygen, natural contamination, tampering.

- Preserves food and prevents food waste.

- Protects consumer goods from being crushed, soiled, or shoplifted.

- Protects children from ingesting drugs and hazardous chemicals.

- Informs consumers of proper use, storage, features, and warranty.

- Allows for easier warehousing, transportation, distributions. Can be handled with large scale mechanical equipment.

Many packages are designed to provide an extra measure of convenience to the consumer. Some packages are ready-to-eat, single serving, disposable, or microwavable.

Packaging is sometimes used to give an extra boost to sales. Multi-packs encourage quantity purchases. The eye appeal of packaging draws shoppers away from the competition. Larger packages use more shelf space and attract shopper's attention.

Most packaging uses material very efficiently, minimizing the energy of production, transportation, and materials cost. The packaging industry continues to refine and improve products. Some improvements allow for thinner, lighter-weight materials that reduce the energy and materials costs, and reduce the amount of garbage going to the landfill. Some improvements make the product more convenient to use, or improve the safety or shelf-life of products.

\section{Packaging Choices}

Some packaging, however, is excessive. Excessive packaging wastes energy and valuable materials, and contributes to the waste disposal problem. Sometimes when improvements are made for convenience sake or to increase shelf-life, the packages produced use more materials, or are more difficult or impossible to re-use or recycle.

Many products are available in a wide choice of packaging options. Juice, for example, can be purchased in cans, bottles, jars, cartons, or singleserve juice boxes. It comes either shelf-stable, refrigerated, or as frozen concentrate. You as a consumer have the choice.

When you shop, choose the type of packaging that has the least environmental impact in terms of energy use, amount of materials used, and recyclability.

The amount of packaging going into the waste stream can be reduced significantly. Your participation will be a positive contribution to the solution of an important problem. You can improve the quality of life for yourself and our society by adopting environmentally appropriate behavior. It's up to you.

You may think your part won't be enough to matter. Your garbage by itself is not a problem. But when you add it to the garbage of your neighbors, your town, your county, the whole state, then the problem has grown to huge proportions.

\section{The Five "R's"}

So do your part. BE AN ENVIROSHOPPER! Follow the five "R's" of Enviroshopping: 
- REDUCE the amount of packaging you buy and throw away.

\section{- RE-USE.}

- RECYCLE whenever possible.

- REJECT packaging that is unsatisfactory.

- RESPOND to producers and retailer to let them know how you feel.

\section{Reduce Packaging}

Reduce your garbage before you buy it -PRECYCLE! Pre-cycling is the most important thing you can do toward solving the waste management problem. If you never buy it and bring it into your home in the first place, then you don't have to "manage" it. You don't have to figure out if it can be reused or recycled. You don't have to dispose of it.

Here are some examples of pre-cycling strategy:

- Begin your Enviroshopping before you go to the store. Take your grocery bags back to the store so you won't need to get new ones every time.

- Take your own shopping bag for small purchases.

- Look for packages that use the least amount of material. Avoid those that use several layers when one would do.

- Buy products in the largest quantity possible in one package. One large jug of cleaner uses less packaging material per ounce than several small bottles. Refill a smaller spray bottle or dispenser from a large jug.

- When it comes to large containers of food, be sure you don't buy more than you can use before it spoils.
- Look for products with re-usable dishes, rather than throw-aways.

- Whenever they are available, buy concentrated products then dilute them at home in a larger reusable container.

- Fresh fruits and vegetables are available unpackaged or packed in trays with a plastic film. Loose produce may become bruised from handling, but you can select just the pieces you want. This uses less packaging.

- $\quad$ "Fast food" restaurants produce a large volume of trash since most of their serving materials are throw-aways. Encourage them to use recycled materials, and to recycle their wastes, or prepare your own food at home. Eat in the restaurant when you can to save the extra pieces of packaging from the drive-thru.

Pre-cycling Saves Energy. Pre-cycling does make a difference. Compare the packaging material in two quart containers and in a one halfgallon container. The two quarts use more packaging than the one half-gallon container. If 70 million American households bought a half-gallon container of milk a week instead of two quarts, they would reduce paper discards by 41.6 million pounds and plastic discards by 5.7 million pounds a year. This would save \$145.6 million in packaging and more than 1 trillion BTU of energy -- enough to heat and cool 7,500 households for an entire year.

Be an Enviroshopper. Think carefully about the convenience of a product compared to its environmental impact. Sometimes you may need to buy an item with more packaging to get just the product you need. Often, however, you can do without the little bit of convenience. You'll save energy, conserve resources, reduce pollution, and possibly save money too.

\section{Reuse Packaging}

Packaging comes in many forms. There is an endless variety of cardboard boxes, metal tins, 
plastic jars, glass jugs. There are bowls, boxes, tubes, trays, and jugs. Packages are compartmented, round and square, plain and fancy, with lids, sprayers, snaps, flaps, seals, and drawstrings. Their uses are as varied as your creativity and determination to make use of these high quality materials. Here are some examples.

- Use divided cookie trays as desk drawer organizers.

- Cut a small plastic container in half lengthwise to make a flour scoop.

- Punch holes in the bottom of a round container to make a flower pot.

- Cover an old wooden box with fabric, add a cushion to the top, and you have a new stool to sit on.

- Polystyrene vegetable trays are good for artists of all ages to mix paints in.

- Drawstring mesh citrus bags make good laundry bags. (Use only for children old enough to handle the string safely.)

- Cover cans with old fabric, wallpaper, and wrapping paper. Use them to support a pretty board on your desk or kitchen counter to add shelf space, or fill with goodies for holiday giving.

- Frozen and microwavable convenience foods often come with their own dish. Re-use these dishes for making your own convenience meals.

- Many types of containers are in demand at schools, child care centers, and senior centers, where they provide resources for the creativity of young and old. Call your local agencies to see what they need.

And of course packages of all kinds can be used for storage. Packages can store items in the shop or garage, the sewing room, the kitchen, the playroom, the bathroom, the office, and the trunk of your car, just to name a few. Packaging is a resource you pay for with every purchase. Think creatively to use and reuse it whenever you can.

\section{Recycle packaging}

Many valuable items don't need to become waste. State law requires Florida's municipalities to reduce our solid waste through recycling. What kinds of packages can you recycle? Aluminum and glass are recyclable. Some paper and some plastic containers can be recycled. Steel or "tin" cans are recyclable. They all are easier to recycle when they are single material packages, rather than a mixture of two or more in one package.

For example, aluminum is 100 percent recyclable. A pound of aluminum that is recycled will yield a pound of "new" aluminum. But some types of packaging are made from several layers of plastic, paper, and aluminum. This aluminum cannot be separated easily, if at all, and so is lost for future use.

Many food packages are made from recycled glass, aluminum, and paper products. Recycled plastic, however, cannot be used for packaging food. Plastic food containers are made of new plastic, as the Food and Drug Administration has not approved recycled plastic for use in food containers.

\section{Recycle Packaging Material}

Recycling glass. Glass is easily recyclable and saves up to 25 percent of the energy compared to making glass from new materials. However, glass is rarely made from 100 percent recycled glass, so the energy savings is usually less than 25 percent. Recycled glass containers can be used for packaging food, and in fact, glass containers can be refilled without recycling. Refilling is the most energy efficient use of glass containers.

Recycling Cardboard and Paper. Recycled cardboard and paper are used to make your grey colored cereal boxes and many other cartons. Recycling paper saves from 24 to 54 percent of the energy for paper manufacturing. 
Recycling steel. Steel is easy to recycle because it can be magnetically separated from other materials. To make steel from scrap takes about half as much energy as making it from its traditional raw materials -- coal, iron ore, and limestone.

Recycling aluminum. The aluminum cans you buy your beverages in were most likely cans before. They are typically recycled back into beverage cans. It's possible for an aluminum can to move from the retailer's shelf, to your home, into the recycling process and back to the store shelf in as little as six weeks. And, it can be recycled over and over again. An aluminum can you buy 20 years from now could contain some of the aluminum you recycled today!

Producing new metal from used aluminum saves 95 percent of the energy needed to produce aluminum from ore. Recycling one 12-ounce aluminum can saves the equivalent of half of that same can (6-ounces) of gasoline.

Recycling Plastic. Some types of plastic are currently recycled in large amounts. Polyethylene terephthalate (PET) is used for making the liter-size soft-drink bottle. It is recycled into such items as ski jackets, carpets, and geotechnical materials like erosion control mesh.

HDPE, or high density polyethylene, is used for the gallon-size milk jug, and is recycled into new containers for non-food items, such as dish detergent or other cleaners.

New Technology. The technology for recycling other types of plastic is still being developed. We also need to develop the infrastructure for collecting, sorting, and processing the plastics into new, useful products.

Plastics of different resin types cannot be recycled together without producing a different type of plastic. To get the same type of plastic after recycling, they need to be sorted by resin type. If the plastics can be separated, as in the two-piece liter-size soft drink bottles, they can be recycled, but separation adds to the cost of recycling. Some recyclers can take a mixture of all types of plastic to produce park benches, fence posts, parking stops, and waterproof "lumber" for piers.

Sometimes it is difficult to tell different plastic types apart. For this reason, the plastic producers have begun to code the containers they make with a number indicating the type of plastic resin used to make the container.

At present it may not be practical to recycle certain types of plastic. For recycling to work, there needs to be a functional, economically feasible, recycling system to convert a particular material into another marketable product.

Closing the Loop. You have a double role in recycling. You provide the raw material from your trash and you need to buy the recycled material after it is made into something new.

Recycling has no end. It progresses in a loop -purchase, use, recycle, reformulate, and resale. It is up to you, as an Enviroshopper, to buy recycled materials whenever you can. Look for the recycled symbol

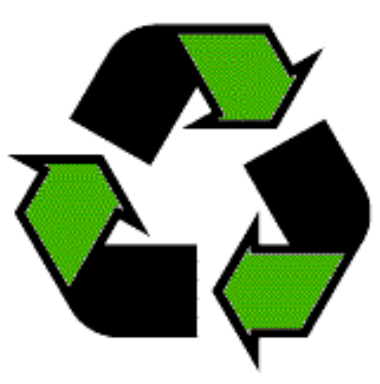
on packages you buy.

Until large-scale markets are developed, recycled materials may cost more than new. But every time you buy a recycled product, you help to increase the market and bring down the cost. When you buy recycled material, you maintain the demand for your empty containers and worn out goods. Do your part to help "close the loop" of recycling.

Recycling is important. It makes good sense to reduce the environmental pollution from energy use and manufacturing, and to extend resources. But recycling is only a part of a complete waste management strategy. Remember the first two "R's" -- Reduce and Reuse. As important as recycling is, it will have far less impact than reducing and reusing. 


\section{Reject Packaging}

When you avoid buying items that are wasteful, environmentally harmful, or of poor quality, you reject those items in favor of those that can be reduced, reused and recycled. The products you buy will determine which companies stay in business, so they pay close attention to your shopping habits.

Your pocketbook is a valuable tool. As an Enviroshopper, you can use it to encourage the kind of packaging that fulfills its necessary functions without excess, and with the least effect on the environment.

\section{Respond}

Your preferences are important to stores and manufacturers who want you to continue buying their products and shopping in their stores. Tell them what you like and what you don't!

Use consumer hotlines. Explain the need for Enviroshopping and why you support it.

Let store managers and manufacturers who are making good environmental choices in their products and packaging know that you recognize and appreciate their effort. You will find the company address on the package of most products.

Make suggestions to stores to eliminate prepackaging of produce. Suggest that they stock refills, and offer larger quantities and sizes of products. Ask them to consider recyclability and source reduction in the products they offer for sale.
You can encourage simpler, less complex packaging. Can label information be printed on a hanging tag or a peel off label, rather than needing a whole package? Less packaging can save money for the manufacturer, the consumer, and the waste manager, and help to protect our environment and save resources.

Encourage local government officials to initiate or expand a recycling program in your community. The technology is available for recycling glass, newspapers, aluminum, steel, and some types of plastics.

Learn as much as you can about the environmental consequences of your actions. Make a commitment to become an Enviroshopper and help to educate others.

\section{Enviroshopping}

Learning new habits can be difficult. You may spend more time in the grocery store trying to find the products that meet your new standards. You may spend a few minutes longer at certain tasks when you buy packaging that is less convenient. You may need to reorganize a kitchen cabinet to make room for reusables and recyclables. But the effort is worth it, and gradually these habits will be easier and easier.

Enviroshoppers can play an important role in reducing the solid waste problem. To actively support the environment in the marketplace, make choices according to the 5 "R's" of Enviroshopping. Every individual's participation is important and does make a difference. 